\title{
Die Effektivität transnationaler Maßnahmen gegen Menschenhandel in Europa
}

Eine Untersuchung des rechtlichen Vorgehens gegen die moderne Sklaverei in der Europäischen Union und im Europarat

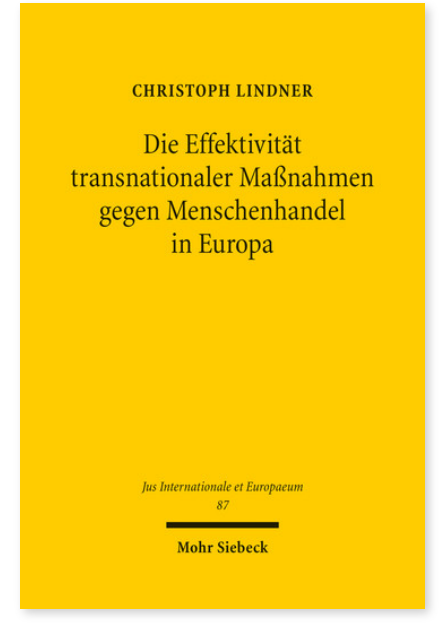

2014. XIX, 286 Seiten. JusIntEu 87

ISBN 978-3-16-153075-3

DOI 10.1628/978-3-16-153075-3

eBook PDF $79,00 €$

ISBN 978-3-16-153043-2

fadengeheftete Broschur 79,00€
Menschenhandel ist ein multipolares Phänomen im Kontext von Migration und organisierter Kriminalität. Doch vor allem ist Menschenhandel in all seinen Erscheinungsformen eine fundamentale Menschenrechtsverletzung, die für eine moderne Gesellschaft und ihren Rechtsstaat nicht hinnehmbar ist. Die Europäische Union und der Europarat haben dies erkannt und insbesondere ihr rechtliches Vorgehen gegen Menschenhandel intensiviert. Aber wie gut ist Europa in seinen Rechtsakten gegen Menschenhandel? Welche Faktoren machen Maßnahmen effektiv, wo liegen Defizite und wie lassen sich diese beseitigen? Christoph Lindner geht diesen Fragen mit Hilfe eines strukturierten Analysemodells nach.

Christoph Lindner Geboren 1984; Studium der Rechtswissenschaft in Regensburg und Sydney; Mitarbeiter am Lehrstuhl für Öffentliches Recht und Völkerrecht an der Universität Regensburg; Consultant für internationale Organisationen im Bereich Flüchtlingsrecht und Menschenhandel; 2013 Promotion zum Dr. jur.; seit Dezember 2013 Rechtsanwalt in München und Rosenheim.

Jetzt bestellen:

https://mohrsiebeck.com/buch/die-effektivitaet-transnationaler-massnahmen-gegen-menschenhandel-in-europa9783161530753?no_cache=1

order@mohrsiebeck.com

Telefon: +49 (0)7071-923-17

Telefax: +49(0)7071-51104 